\title{
Does Metaethics Rest on a Mistake?
}

\author{
Mark Eli Kalderon
}

One consequence of the professionalization of philosophy is its ever increasing specialization. Within the normative domain, what has come to be known as metaethical inquiry is increasingly conducted independently of substantive ethical reflection. Even if this trend is intelligible given the economic and institutional pressures that spawned it, it is reasonable to wonder if insights are lost and distor tions and illusions introduced by focusing exclusively on the limited perspective of metaethical inquiry. Dworkin laments this trend and is skeptical about contemporary metaethics.

The division between "first-order", "substantive" normative inquiry and "secondorder", "meta" normative inquiry has come to seem natural to us and is fundamental to the way we standardly present these topics in our teaching. But it has not always been so. Thus, for example, Rawls (2000) has claimed that the moral philosophies of Hume and Kant cannot intelligibly be presented in this way. Instead, they ex$^{-}$ emplify what he calls a "philosophical ethics". Both Hume and Kant address metaphysical and epistemological questions about ethics, but they do so in a way that is not independent from substantive ethical reflection.

Dworkin, in the first part of fustice for Hedgehogs, presents an alternative to the prevailing orthodoxy that is distinct from Rawlsian philosophical ethics but similar to it. According to Dworkin, all second-order, meta-normative claims are to be understood, fundamentally, as first-order, substantive, normative claims. If true, then meta-normative inquiry, or what passes for it, could not intelligibly be conducted independently of substantive, normative reflection. If Dworkin is right, then contemporary metaethics rests on a mistake. (As will emerge, this echo of Prichard I9I2 is deliberate.)

Dworkin's brief against metaethics is a small part of a larger case for the unity of value. The unity of value is the great idea of the book in virtue of which Dworkin counts as a hedgehog set against the prevailing orthodoxy of foxes. The unity of value is not the claim that there exists one master value to which all other values must reduce; rather, it is a distinct value monism that claims that all values are mutually dependent. What it is to be a value of a certain kind will depend upon what it is to be a value of a distinct kind. Consider the following analogy. Schaffer (2007, 2008, 2009, 2010) distinguishes between existence monism, according to 
which only one thing exists - the world, and priority monism. According to priority monism, the world may contain a plurality of parts, and hence there exists more than one thing, but these parts depend upon the whole whose parts they are. Thus whereas Parmenides is an existence monist - there exists only the one being of the way of truth, Hegel is a priority monist. The unity of value is more akin to priority monism than to existence monism. The analogue of existence monism would be the claim that there exists only one master value to which all other values must reduce. In contrast, the unity of value can allow for a plurality of irreducible values, it is just that these values are not independent of one another but are rather mutually dependent.

According to the unity of value, distinct values, such as liberty and equality, mutually depend upon one another in such a manner that the reasons they give rise to could not practically conflict. What it is possess liberty presupposes the value of equality: "You cannot determine what liberty requires without also deciding what distribution of property and opportunity shows equal concern for all" (Dworkin, $20 I I, 4)$. But if that is right, then the demands of liberty could not practically conflict with the demands of equality. In this way, the advocate of the unity of value will resist the Pyrhhonian skepticism, revived in modern times by Montaigne, that proceeds from the argument from conflicting values (for a useful to discussion of such argument forms see Annas and Barnes, 1985). As thus far presented, the unity of value is a complex philosophical doctrine, but, as should be clear from the form that Dworkin's skepticism about metaethics takes, and as Dworkin himself insists, it is also a creed.

An aspect of the overall case for the unity of value sheds light on Dworkin's skeptical attitude towards metaethics. Specifically, Dworkin's views about the nature of interpretation and the part they play in the argument for the unity of value are relevant to his skepticism about metaethical inquiry. Interpretation, for Dworkin, is an important mode of understanding that finds application in such diverse ar eas as literary criticism, history, and law. Despite the diversity of application, this mode of understanding nevertheless displays a common structure. Dworkin (2OII, I30-I34) provides an account of this common structure in his value theory of interpretation. According to the value theory of interpretation, there are different genres of interpretation. To interpret something one must first assign it to a particular genre of interpretation. A given genre is governed in part by a value or range of values. Thus, for example, in interpreting a poem one may be primarily interested in poetic beauty, say. Thus to interpret something one must second identify the value or values that govern the given genre of interpretation. Finally, one must provide an interpretation that best realizes the governing value or values of the given genre of interpretation.

Interpretation, on the value theory, is value laden. It is also pervasive-it is a 
mode of understanding deployed, inter alia, in our daily commerce with our fellows. If interpretation is value-laden and pervasive, then since it is an inherently truthseeking activity, values will themselves be pervasive. Moreover, the values posited by our best interpretations will display a kind of unity. Interpretation is inherently holistic, its methods coherentist. The best interpretation of liberty will make it cohere with equality, and indeed with other important political values. And since interpretation is a truth-seeking activity in virtue of which it counts as a genuine mode of understanding, pervasive values must display the unity required if they are to so cohere.

Let us return to Dworkin's brief against metaethics. Begin with the ordinary view. According to Dworkin (2OII, 26-28) we ordinarily take out moral judgements to be true, indeed to be true independently of our judging them to be true. Two questions naturally arise for the ordinary view:

I. What makes our moral judgments true?

2. When are we justified in taking a moral judgment to be true?

Worries that these questions lack adequate answers animates contemporary metaethical discussion. Begin with the first question. What makes our moral judgments true? What do the moral facts consist in? It can seem that the ordinary view is inconsistent with physical or psychological facts making our moral judgments true. But then what could make them true? The distribution of morally charged particles? Worries arise with the second question as well. How can we know that a moral judgment is true or even be justified in taking a moral judgment to be true? We don't know the moral facts in the same way that we can know the physical facts. Some physical facts are perceptible, but, on the ordinary view, the moral facts are not perceptible, at least not in the way that some physical facts are (see Harman, I977, for a classic statement of this view).

These worries motivate skepticism about the ordinary view. Dworkin (20II, 30-33) marks two orthogonal distinctions between, on the one hand, internal and external skepticism and, on the other hand, error and status skepticism. The distinction between internal and external skepticism concerns the grounds of such skepticism. Roughly, whereas the internal skeptic relies on the truth of substantive moral claims as premises, the external skeptic relies on second-order claims about morality. The distinction between error and status skepticism concerns the form that such skepticism takes. The error skeptic claims that all moral judgments are false. The status skeptic denies as well that our moral judgments are true but in a different way. Whereas the ordinary view implicitly understands moral judgements as objective descriptions of reality, the status skeptic claims that they have a different status. They function not to describe objective moral reality but have some other, perhaps expressive, function. 
These orthogonal distinctions combine in the following manner. Whereas $\mathrm{ex}^{-}$ ternal skepticism may take the form of either an error or status skepticism, internal skepticism may be, at best, a partial error theory since it relies on the truth of a substantive moral claim as a premise. Moreover Dworkin (20II, 33) denies (without explaining) that there could be an internal status skepticism. Dworkin's focus, how ever, is on external skepticism. The internal skeptic at least agrees with Dworkin that a substantive moral argument is required to call into question the truth of a particular moral claim.

The external skeptic is committed to the existence of a nonmoral argument that our moral judgments are not true (either because they are false or because they are incapable of truth or falsity). This is the mistake upon which, more generally, contemporary metaethics rests. For there is no such sound nonmoral argument. Indeed, this is enshrined in what Dworkin calls Hume's Principle:

$[N]_{0}$ series of propositions about how the world is, as a matter of scientific or metaphysical fact, can provide a successful case on its own-without some value judgment hidden in the interstices - for any conclusion about what ought to be the case. (Dworkin, 20II, 44)

Contrast external skepticism with Dworkin's preferred answer to the two questions about the ordinary view. What makes our moral judgments true is the existence of a sound moral argument for them. Moreover, we are justified in taking a moral judgment to be true when we are justified in taking there to be a sound moral argument for that judgment. These answers are bound to disappoint if one believed that an informative and illuminating answer to these questions must ground morality in something else, if an informative and illuminating answer must take the form of a sound nonmoral argument. This is where the analogy with Prichard (I9I2) is apt. Prichard and Dworkin oppose forms of inquiry that aspire to knowledge of nonmoral arguments for moral claims. Moreover, each oppose such projects by denying that the relevant knowledge exists - there is no sound nonmoral argument to be known. They differ only in their reaction to this lack. Prichard suggests that we can know without proof at least certain moral claims. Dworkin, in contrast, claims that moral arguments for moral truth may not count as proof if your standard for proof requires the argument to be nonmoral. But we can nonetheless come to know the truth of moral claims by virtue of possessing a sound moral argument and recognizing it as such. Dworkin's reaction is a manifestation of the coherentism that is constitutively involved in our interpretive practices.

The external skeptic is not alone in making this mistake. A metaphysically ambitious moral realist can agree with the external skeptic that a sound nonmoral argument is needed to establish the truth of a moral claim, it is just that the skeptic's pessimism about the existence of such an argument is here matched by the 
realist's optimism. The metaphysically ambitious realist shares the external skeptic's mistake- no such argument is needed and none is to be found.

Let us turn now to Dworkin's case against external skepticism. The position counts as skeptical since it denies the existence of objective moral truth, either because all moral judgements are false or because moral judgments have a nontruth-evaluable status.

Begin with the former alternative, error skepticism. According to error skepticism all moral judgments are false. According to Dworkin (2OII, 46), any sound argument for error skepticism could not count a moral claim among its premises. Moral claims are meant to be false in which case a moral argument for error skepticism would, by its own lights, be unsound. (Again a moral argument at best supports a partial error theory and would result in a form of internal skepticism.) So external error skepticism must be underwritten by a nonmoral case for global error. But, Dworkin maintains, this is implausible flouting, as it does, Hume's Principle. Any interesting and coherent error skepticism will inevitably de developed as a form of internal skepticism. As a model of such skepticism, think of the view that God is the source of permissions and prohibitions, and since God does not exist, nothing is forbidden. That skepticism relies on a moral claim-that God is the source of permissions and prohibitions - as a central premise. Indeed Dworkin (20II, 47-5I) discusses Mackie's (I977) arguments as arguments for internal error skepticism.

Against the latter alternative, status skepticism, Dworkin develops a novel challenge to its very coherence. Recall, the status skeptic denies that moral judgements are objective descriptions of reality, maintaining, instead, that they have a different status. They function not to describe objective moral reality but have some other, perhaps expressive function. Against the status skeptic, Dworkin invites us to consider a moral claim and the corresponding ascription of objective truth:

I. Torture is wrong.

2. Torture is wrong as a matter of objective truth that does not depend on anyone's attitudes.

Dworkin maintains that, at least in ordinary discourse, the latter merely makes explicit what an ordinary speaker would be implicitly committed to in asserting the former. But if that's right, then no one could coherently accept the former claim and deny the latter. But this is exactly what the status skeptic proposes to do. Dworkin considers two responses the status skeptic might make to this challenge. First, the status skeptic might insist that our linguistic practices provide sufficient evidence that there really is two distinct speech acts, expressing a moral conviction and describing that conviction as true. And that while the former is in order, the latter embodies a philosophical mistake. Second, the status skeptic may 
concede that in ordinary discourse there is no distinction in speech act between expressing a moral conviction and describing that conviction as objectively true, but that in other, extraordinary discourse-in the present instance, philosophical discourse - the distinction can be marked between a moral claim and its objective truth. This latter strategy Dworkin associates with Rorty.

Neither strategy will do.

Dworkin doubts that there is in fact sufficient linguistic evidence to distinguish the two speech acts. Though his case here is hampered by not actually considering the kind of linguistic evidence that noncognitivists have brought to bear. Though I confess that I may not fully understand the full force of Dworkin's argument, it remains unclear to me why such a case could not be made by the status skeptic. Perhaps if a claim is to describe objective reality it must play a certain functional role in public discourse and in the psychology of its speakers. Why could we not discover that moral claims fail to play this role though they play a similar enough role to make belief to the contrary explicable?

Dworkin doubts as well that a suitable distinction in meaning can be found to distinguish truth-ascriptions as they figure in ordinary and extraordinary discourse and so Rorty's distinction between language games fails.

Dworkin develops his views abut interpretation in part two. However, his brief agains metaethics in part one is usefully understood in light of it. This is made clear in his preface, "Baedeker", where Dworkin presents the topics of Fustice for Hedgehogs in reverse order to emphasize the interconnectedness of his themes and to motivate his initial discussion of metaethics as relevant to those whose interest are more political. Interpretation, at least as applied to normative thought and talk, is conceptual in the sense that it involves explication of conceptions of such abstract values as justice and equality. The best such conception will better explain its application to paradigm cases and will display the best overall coherence with other related values. This interpretivist paradigm developed in part two is deployed throughout the rest of the book in Dworkin's discussion of ethics, morality, and politics. However, it is also directly relevant to understanding Dworkin's "disappointing" answers to the two questions about the ordinary view. Recall, according to Dworkin, what makes our moral judgments true is the existence of a sound moral argument for them. This is just what you would expect from the coherentist epistemology that flows form our interpretative practices. That a moral judgment follows from our best conception of the values it attributes just would be for that judgment to be true.

Dworkin's answer to the question what makes our moral judgements true may be disappointing but not because it essentially involves the existence of a sound moral argument for the truth of a moral judgment, but for thinking that an answer to what makes a judgment true could so much as consist in an argument for the truth of that 
judgment. That is to say, Dworkin's answer can seem unacceptably verificationist in offering an epistemological answer to a metaphysical question. The question, what makes a judgment true, is metaphysical. It asks how the world must be if it is to confer truth on a judgment. The answer, the existence of a sound argument that the judgment is true, can seem epistemological. A sound moral argument may establish the truth of a moral judgment, but that is an epistemological claim. Absent some verificationist assumption, it does not follow that the sound moral argument makes the moral judgment true. If the world is as it must be if it is to confer truth on the judgment, then there exists, at least potentially, a sound argument that the judgment is true. But the existence of such an argument is not what makes the judgment true; rather, it is the world being as it is. Or so goes the verificationist worry.

Dworkin's discussion of supervenience in the chapter on moral responsibility in part two is meant to address the verificationist worry. What's at work here is not some unacceptably verificationist assumption but a distinctive feature of the evaluative. It's slogan might be: The evaluative is essentially intelligible. The evaluative supervenes on the nonevaluative. A consequence of this that value judgments could not be barely true in the sense that if two worlds differ in the existence of some value they must differ as well in some nonevaluative respect. From this Dworkin concludes that:

When a value judgment is true there must be a reason why it is true. It can't be just true. (Dworkin, 2OII, II4)

In nonevaluative domains, judgments can be barely true, and if they are, then there is no reason why they are true, they just are true. So there is no general verificationist assumption at work here, nor any appeal to the principle of sufficient reason. Rather, it is distinctive of the evaluative that it be intelligible. Nothing is wrong for no reason, that would be not only capricious but unintelligible. And the evaluative is essentially intelligible.

I believe that it is genuine insight that the evaluative is essentially intelligible. And one with an ancient precedent-arguably Heraclitus is an advocate, despite his reputation for obscurity. I remain skeptical, however, about Dworkin's argument from supervenience. If one is persuaded by Kripke's and Putnam's cases for the existence of a posteriori necessity, then one worry would be that Dworkin's reasoning hasn't ruled out one relevant possibility - that the supervenience of the evaluative on the nonevaluative may mean that the nonevaluative necessitates the evaluative without a priori entailing it. This has the consequence that knowledge of that which necessitates the evaluative need not yield knowledge of that which is necessitated. Moreover, it can seem that knowledge of the evaluative does not require knowledge of the nonevaluative upon which it supervenes. The value of 
a pound coin supervenes on complex legal and institutional arrangements the essential details of which I am largely ignorant, and yet I can know its worth. And the worry is that the insight into what is distinctive of the evaluative, that it is essentially intelligible, has been obscured by reasoning that if not committed to a general verificationism, seems nonetheless committed to a local verificationism in the way it interweaves the metaphysical and the epistemological. It is not clear to me at least why the essential intelligibility of the evaluative should take the form of a local verificationism about the evaluative. I do not take this line of objection to be decisive. I do, however, take it to show that Dworkin's reasoning here is incomplete.

What's at stake is not just Dworkin's answer to what makes our moral judgments true, but that part of his case for the unity of value that rests on the value theory of interpretation. Consider Dworkin's optimism that the judgments entailed by the interpretation that elaborates our evaluative conceptions in a way that promotes best overall coherence and explanatory power will in fact be true. One way, not the only way, to defuse such optimism is if there is in fact no way to coherently integrate our ordinary evaluative conceptions in this way. Early on Dworkin (20II, 30) dismisses postmodernism:

An unsophisticated form of such skepticism, which is often called "postmodernism," has been in vogue in the unconfident departments of Western universities: in faculties of art history, comparative literature, and anthropology for example.

Perhaps this was a mistake. For at least some of the time, postmodern skepticism calls into question the very possibility of an interpretation of that could render all our evaluative conceptions coherent and mutually intelligible. The possibility of such an interpretation would be rejected, albeit on different grounds, by Derrida (I998) and Lyotard (I984). Nor is doubts about the possibility of elaborating our ordinary evaluative conceptions in a way that maximizes overall coherence and explanatory power limited to unconfident departments in Western universities. Think of the way in which MacIntyre (I98I) extends Anscombe's (I958) argument in "Modern Moral Philosophy". MacIntyre claims that our present moral discourse is broken since it is now conducted in circumstances divorced from the historical circumstances that lent it intelligibility. The point of alluding to such radical forms of skepticism is just to highlight the way in which the source of Dworkin's optimism here is a substantive commitment, to moral truth not outstripping the interpretation that best maximizes overall coherence and explanatory power and to the existence of such an interpretation. But when the source of this commitment is seen to be substantial in this way, then it can also seem to be verificationist, or at least the expression of a coherentist theory of evaluative truth. 
Having expressed some doubts, let me stress some important points of agreement.

First, the essential intelligibility of the evaluative is an important insight, and one that has moral and political significance. If I have expressed some reservations, they were less about the fundamental insight than about how that insight was expressed in Dworkin's argument from supervenience. But Dworkin is right about the fundamental insight and right to emphasize its moral and political significance. Moreover, it is natural to see how this might be leveraged in an argument for the unity of value. If it is of the nature of value that values be intelligibly realized then actually realized values are at least guaranteed not to conflict. Moreover, the essential intelligibility of the evaluative may be a metaphysical doctrine, but it is also, importantly, an ethical doctrine. In ethical disputes that turn on apparently conflicting values, the conflict is merely apparent. Recognition of this will affect how one conducts this dispute- by actively looking for mutual intelligibility which must be there if the disputants are each genuinely responding to some ethically significant evaluative aspect of their common circumstance. So even if you doubt that all competing metaphysical views about ethics are competing ethical views, at least one metaphysical view about ethics is also an ethical view.

Second, perhaps Dworkin is right to suspect the effects of specialization. These effects involve ring-fencing areas of concern and a consequent narrowing of focus. Given these limitations, there exists the dark possibility of perspective induced distortions or illusions. Thus Dworkin, echoing Prichard, claims that we should abandon metaethical inquiry since it rests on a mistake. Specifically, it is a form of inquiry that aspires to knowledge of sound nonmoral arguments for our moral claims but no such arguments exist. Even if one is not convinced that perspective induced distortions or illusions arise in this way, there is at least always the possibility, envisioned by Dworkin, of the metaphysical and ethical essentially interacting, of insights lost to this more narrow perspective. In this Dworkin and Rawls are in agreement. This was part of Rawls point in emphasizing how the moral philosophies of Hume and Kant could not be intelligibly presented while respecting the ring-fenced concerns of the orthodox curriculum. So even those unconvinced by Dworkin's skepticism about metaethical inquiry still have cause for concern about the effects of specialization in normative theorizing.

fustice for Hedgehogs is an ambitious book, and its quarry, the unity of value, is a suitably grand idea. Dworkin writes with his characteristic energy, and the book literally brims with ideas. One distinct literary pleasure is the way the book itself mir rors its central doctrine (a fact that Dworkin alludes to in "Baedeker"). Dworkin's themes are essentially interconnected and display the same kind of mutual dependence ascribed to value in his value monism. The interpretive task of reading with understanding itself mirrors and provides support by example for many of the cen- 
tral doctrines of the book. And when done self-consciously, this gives rise to a distinct literary pleasure. Fustice for Hedgehogs is a modernist achievement both in doctrine and as philosophical literature.

\section{References}

Julia Annas and Jonathan Barnes. The Modes of Scepticism: Ancient Texts and Modern Interpretations. Cambridge University Press, Cambridge, I985. 2

G. E. M. Anscombe. Modern moral philosophy. Philosophy, 33(I24):I-I9, I958. 8

Jacques Derrida. Of Grammatology. Johns Hopkins University Press, I998. 8

Ronald Dworkin. Fustice for Hedgehogs. Belknap Press of Harvard University Press, Cambridge, MA, 2OII. 2, 3, 4, 5, 7, 8

Gilbert Harman. The Nature of Morality. Oxford University Press, New York, I977. 3

Jean-Francois Lyotard. The Postmodern Condition: A Report on Knowledge (Theory and History of Literature, Volume Io). University Of Minnesota Press, Ist edition, I984. 8

Alisdair MacIntyre. After Virtue. Notre Dame University Press, South Bend, IN, I98I. 8

J. L. Mackie. Ethics: Inventing Right and Wrong. Penguin, I977. 5

H. A. Prichard. Does moral philosophy rest on a mistake? Mind, 2I, I9I2. I, 4

John Rawls. Lectures on the History of Moral Philosophy. Harvard University Press, Cambridge, MA, 2000. I

Jonathan Schaffer. From nihilism to monism. Australasian fournal of Philosophy, 85 (2):I75-I9I, 2007. I

Jonathan Schaffer. Monism. In Stanford Encyclopedia of Philosophy. 2008. URL http: //plato.stanford.edu/entries/monism/. I

Jonathan Schaffer. On what grounds what. In David Chalmers, David Manley, and Ryan Wasserman, editors, Metametaphysics: Nerw Essays on the Foundations of Ontology, chapter I2, pages 347-383. Oxford University Press, Oxford, 2009. I

Jonathan Schaffer. Monism: The priority of the whole. Philosophical Review, II9(I): $3^{-7} 76$, 20IO. I 